\title{
On results of $\mathrm{Y}-89$ Irradiation with deuteron beam on QUINTA-assembly "E+T - RAW" using Nuclotron (JINR Dubna)
}

\author{
M.Bielewicz ${ }^{1}$, S.Kilim, A.Polanski, E.Strugalska-Gola, M.Szuta, A.Wojciechowski \\ National Centre for Nuclear Research \\ Otwock-Świerk 05-400, Poland \\ E-mail:m.bielewicz@cyf.gov.pl; s.kilim@cyf.gov.pl; polanski@jinr.ru; elasg@cyf.gov.pl; \\ mszuta@cyf.gov.pl; andrzej@cyf.gov.pl
}

\section{Adam, M. Kadykov, V. Pronskich, S. Tyutyunnikov}

Joint Institute for Nuclear Research

141980 Dubna, Russia

E-mail: jadam@nusun.jinr.ru; kadykov@jinr.ru; vspron@fnal.gov; tsi@sunse.jinr.ru

\section{Wagner, O. Svoboda}

Nuclear Physics Institute of ASCR

25068 Rez, Czech Republic

E-mail:wagner@ujf.cas.cz; svoboda@ujf.cas.cz

\section{Chilap}

CPTP "Atomenergomash"

Moscow, Russia

E-mail: chilap@cftp-aem.ru

\section{Collaboration "E\&T - RAW"}

Experimental values of high energy neutron flux in three energy ranges (11.5-20.8, 20.8-32.7, 32.7-100 MeV) and spatial distributions of ${ }^{88} \mathrm{Y},{ }^{87} \mathrm{Y},{ }^{86} \mathrm{Y}$ and ${ }^{85} \mathrm{Y}$ isotope production are presented for a QUINTA assembly. Deuteron beam energy range was from 2.0 to $6.0 \mathrm{GeV}$. Monte Carlo simulation using MCNPX 2.6 code of the neutron flux density is roughly in agreement with the obtained experimental data.

XXI International Baldin Seminar on High Energy Physics Problems September 10-15, 2012

JINR, Dubna, Russia

1

Speaker 


\section{Introduction.}

This work is done within the project and collaboration „Energy plus Transmutation of Radioactive Wastes" (E\&T - RAW) for investigations of physical aspects, energy production and transmutation of radioactive nuclear waste using relativistic beams produced bythe JINR Nuclotron, Dubna, Russia.[1]

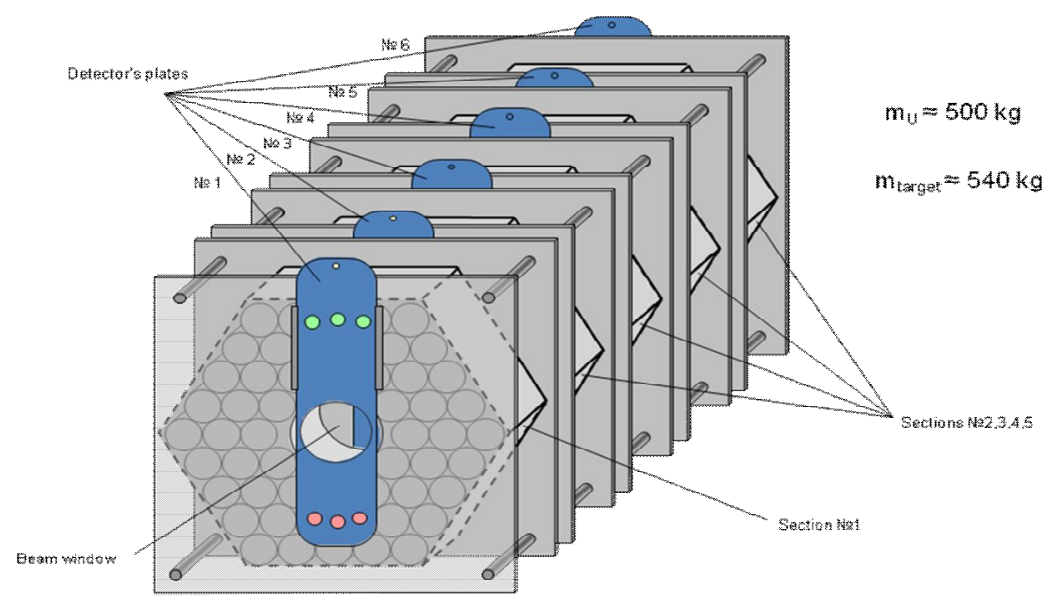

Fig. 1. Quinta assembly in 3D. We can see 6 section of uranium blanket (grey cylinders) and 6 plate with detectors (blue plate). Firs section is without uranium target.

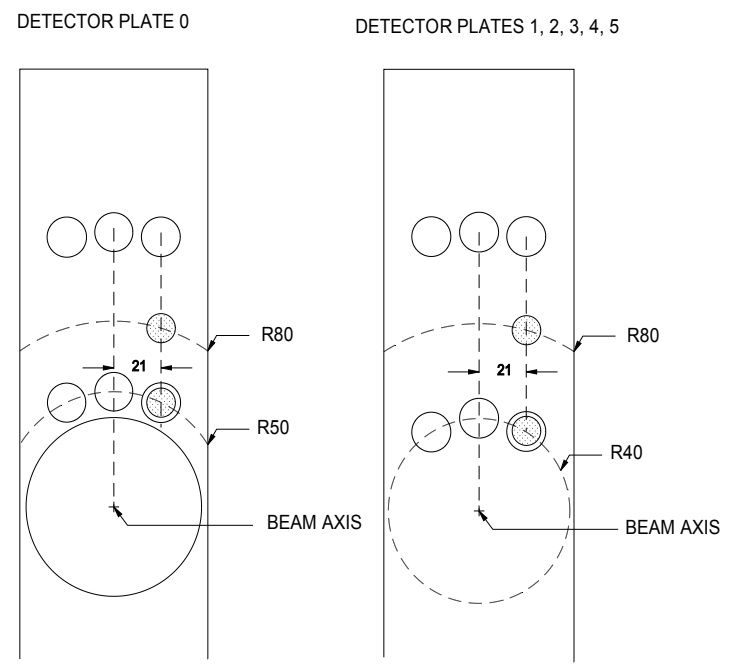

Fig. 2 Location of Yttrium detectors on the detector blue plates (see Fig. 1). 
Twelve Yttrium (Y-89) activation detectors were placed in the Quinta U/U assembly on the detector plates in front of, between the five sections, and on the end of the $\mathrm{U} / \mathrm{U}$ assembly in two radial positions (distances from axis 4 and $8 \mathrm{~cm}$; see Fig. 2). The Quinta $U / U$ assembly is presented in Fig. 1. The Yttrium detectors have one stable isotope (Y-89) with several threshold reaction channels -easy to detect (enough half life time). First threshold reaction with energy $11.5 \mathrm{MeV}$ is $(\mathrm{n}, 2 \mathrm{n})$ giving ${ }^{88} \mathrm{Y}$. The next reaction are for energies 20.8, 32.7, 42.1 and 54.4 $\mathrm{MeV}$. After irradiation Y-89 detectors were measured on HPGe spectrometer. Taking into account necessary corrections and using DEIMOS program [2], [3], we have determined isotope production per one gram of sample and per one beam deuteron (called B parameter) at specified positions of the $\mathrm{U} / \mathrm{U}$ assembly. Below we present results from three experiments from March 2011 for deuteron energy beam 2, 4 and $6 \mathrm{GeV}$. The next experiments was done in December 2011 for deuteron beam 1 and $4 \mathrm{GeV}$, but we present only some comparisons for energy beam 4 $\mathrm{GeV}$. In case of the experiments in December 2011 the Quinta assembly was shielded by lead box.

\section{Experiment}

Different isotopes produced by the neutrons generated in the QUINTA U/U assembly irradiated by the deuteron beam of $2.00,4.00$ and $6.00 \mathrm{GeV}$ give to us ${ }^{88} \mathrm{Y},{ }^{87} \mathrm{Y},{ }^{86} \mathrm{Y}$ and ${ }^{85} \mathrm{Y}$ (Table 1, 2, and 3 ) isotopes production in the assembly from $(\mathrm{n}, \mathrm{xn})$ reaction.

\begin{tabular}{|c|c|c|c|c|c|c|c|}
\hline \multirow{2}{*}{$\begin{array}{c}\text { Residual } \\
\text { nuclei, } \\
T_{1 / 2}, \\
\text { Used } \gamma \text {-lines }\end{array}$} & \multirow{2}{*}{$\begin{array}{l}\text { Radius } \\
{[\mathrm{cm}]}\end{array}$} & \multicolumn{6}{|c|}{$B\left[10^{-6} g^{-1} d^{-1}\right]$} \\
\hline & & 0 & 1 & 2 & 3 & 4 & 5 \\
\hline${ }^{88} Y$ & 4.0 & 2.04 & 14.6 & 39.9 & 14.6 & 5.83 & 2.13 \\
\hline $\begin{array}{c}\mathrm{T}_{1 / 2}=106.65 \mathrm{~d} \\
\mathrm{E} \gamma=898.0 \mathrm{and} \\
1836.0 \mathrm{keV}\end{array}$ & 8.0 & 0.824 & 5.61 & 11.2 & 7.26 & 3.53 & 1.39 \\
\hline${ }^{87} Y$ & 4.0 & 0.862 & 6.38 & 22.6 & 7.70 & 3.43 & 1.49 \\
\hline $\begin{array}{c}\mathrm{T}_{1 / 2}=3.32 \mathrm{~d} \\
\mathrm{E} \gamma=388.5 \mathrm{and} \\
484.8 \mathrm{Kev}\end{array}$ & 8.0 & 0.534 & 2.39 & 5.94 & 4.31 & 2.87 & 0.943 \\
\hline${ }^{86} \mathrm{Y}$ & 4.0 & 0.219 & 1.42 & 7.82 & 2.66 & 1.13 & 0.479 \\
\hline $\begin{array}{c}T_{1 / 2}=0.614 \mathrm{~d} \\
E \gamma=1076.0 \mathrm{keV}\end{array}$ & 8.0 & 0.106 & 0.591 & 1.72 & 1.12 & 0.535 & 0.247 \\
\hline${ }^{85} Y$ & 4.0 & 0.068 & 0.364 & 2.69 & 0.853 & 0.386 & 0.159 \\
\hline $\begin{array}{l}T_{1 / 2}=d \\
E \gamma=k e V\end{array}$ & 8.0 & 0.042 & 0.128 & 0.535 & 0.391 & 0.221 & $0.144 \mathrm{E}$ \\
\hline
\end{tabular}

Table 1. Results (isotope production- parameter B) from experiment in march 2011 with deuteron beam $2.0 \mathrm{GeV}$. 
The error of spatial distributions of ${ }^{88} \mathrm{Y},{ }^{87} \mathrm{Y},{ }^{86} \mathrm{Y},{ }^{85} \mathrm{Y}$ isotope production are from $7 * 10^{-8}$ to $1 * 10^{-6}[\mathrm{n} / \mathrm{g} * \mathrm{~d}]$ respectivly. It means that error is not so big (few percent). Total weighted averages of all measurements number of deuterons from the beams are $1.44(14)^{*} 10^{13}$ for $2 \mathrm{GeV}, 1.42(18) * 10^{13}$ for $4 \mathrm{GeV}$ and $1.94(20) * 10^{13}$ for $6 \mathrm{GeV}$ [11], during the time of irradiation equal to $63600 \mathrm{~s}, 66600 \mathrm{~s}$ and $63600 \mathrm{~s}$ respectively.

The main feature of the experimental spatial distribution of ${ }^{88} \mathrm{Y},{ }^{87} \mathrm{Y},{ }^{86} \mathrm{Y}$ and ${ }^{85} \mathrm{Y}$ is that the maximum isotope production is at about $13 \mathrm{~cm}$ from the front of the target and that the yield is decreasing with increasing radial distance from the target axis. Look at figures Fig. 3 to Fig. 6.

\begin{tabular}{|c|c|c|c|c|c|c|c|}
\hline \multirow{2}{*}{$\begin{array}{c}\text { Residual } \\
\text { nuclei, } \\
T_{1 / 2}, \\
\text { Used } \gamma \text {-lines }\end{array}$} & \multirow{2}{*}{$\begin{array}{c}\text { Radius } \\
{[\mathrm{cm}]}\end{array}$} & \multicolumn{6}{|c|}{$B\left[10^{-6} \mathrm{~g}^{-1} \mathrm{~d}^{-1}\right]$} \\
\hline & & $\begin{array}{r}\text { Axial } \\
0\end{array}$ & 1 & 2 & 3 & 4 & 5 \\
\hline${ }^{88} \mathrm{Y}$ & 4.0 & 3.08 & 23.7 & 81.6 & 31.5 & 14.1 & 5.04 \\
\hline $\begin{array}{c}T_{1 / 2}=106.65 \mathrm{~d} \\
E \gamma=898.0 \text { and } \\
1836.0 \mathrm{keV}\end{array}$ & 8.0 & 1.90 & 10.9 & 19.6 & 15.5 & 6.98 & 2.96 \\
\hline${ }^{87} Y$ & 4.0 & 1.40 & 7.98 & 39.0 & 14.7 & 67.9 & 27.6 \\
\hline $\begin{array}{c}\mathrm{T}_{1 / 2}=3.32 \mathrm{~d} \\
\mathrm{E} \gamma=388.5 \mathrm{and} \\
484.8 \mathrm{Kev}\end{array}$ & 8.0 & 0.917 & 4.79 & 10.8 & 8.66 & 4.44 & 2.06 \\
\hline${ }^{86} \mathrm{Y}$ & 4.0 & 0.288 & 2.29 & 14.7 & 5.38 & 2.37 & 1.09 \\
\hline $\begin{array}{c}T_{1 / 2}=0.614 \mathrm{~d} \\
E \gamma=1076.0 \mathrm{keV}\end{array}$ & 8.0 & 0.232 & 1.20 & 2.90 & 2.56 & 1.21 & 0.580 \\
\hline${ }^{85} \mathrm{Y}$ & 4.0 & 0.078 & 0.60 & 5.09 & 1.69 & 0.815 & 0.355 \\
\hline $\begin{array}{l}T_{1 / 2}=d \\
E \gamma=k e V\end{array}$ & 8.0 & 0.079 & 0.342 & 0.932 & 0.937 & 0.437 & 0.253 \\
\hline
\end{tabular}

Table 2. Results (isotope production- parameter B) from experiment in march 2011 with deuteron beam $4.0 \mathrm{GeV}$.

Threshold energy for the ${ }^{89} \mathrm{Y}(\mathrm{n}, 5 \mathrm{n}){ }^{85} \mathrm{Y}$ is equal to $42.1 \mathrm{MeV}$ what is higher than the maximum energy of evaporated neutrons $(40 \mathrm{MeV})$ during spallation. By using the Tables 1, 2 and 3 the spatial distributions of ${ }^{88} \mathrm{Y},{ }^{87} \mathrm{Y},{ }^{86} \mathrm{Y}$ and ${ }^{85} \mathrm{Y}$ isotope production (the parameter B) for the deuteron beam of 2.0, 4.0 and $6.0 \mathrm{GeV}$ are plotted in 3D graphs. In Fig. 3 to 5 we present spatial distribution (radial \& axial) of ${ }^{88} \mathrm{Y}$ production. You can compare differences and maximum levels of isotopes productions. We present graphs for the deuteron beam energy $2 \mathrm{GeV}$ (Fig. 3), $4 \mathrm{GeV}$ (Fig. 4) and $6 \mathrm{GeV}$ (Fig. 5). Additionally we put one graph for distribution of ${ }^{85} \mathrm{Y}$ production with the deuteron beam energy $6 \mathrm{GeV}$ (Fig. 6) 


\begin{tabular}{|c|c|c|c|c|c|c|c|}
\hline \multirow{3}{*}{$\begin{array}{c}\text { Residual } \\
\text { nuclei, } \\
T_{1 / 2}, \\
\text { Used } \gamma \text {-lines }\end{array}$} & \multirow{2}{*}{$\begin{array}{c}\text { Radius, } \\
\text { [cm] }\end{array}$} & \multicolumn{6}{|c|}{$B\left[10^{-6} g^{-1} d^{-1}\right]$} \\
\hline & & & & & & & \\
\hline & & $\begin{array}{r}\text { Axial } \\
0\end{array}$ & 1 & 2 & 3 & 4 & 5 \\
\hline${ }^{88} Y$ & 4.0 & 4.31 & 32.8 & 110.0 & 48.3 & 22.2 & 10.2 \\
\hline $\begin{array}{c}\mathrm{T}_{1 / 2}=106.65 \mathrm{~d} \\
\mathrm{E} \gamma=898.0 \mathrm{and} \\
1836.0 \mathrm{keV}\end{array}$ & 8.0 & 2.75 & 12.4 & 27.4 & 21.1 & 11.8 & 5.74 \\
\hline${ }^{87} Y$ & 4.0 & 1.67 & 12.8 & 57.2 & 23.1 & 12.1 & 5.16 \\
\hline $\begin{array}{c}\mathrm{T}_{1 / 2}=3.32 \mathrm{~d} \\
\mathrm{E} \gamma=388.5 \text { and } \\
484.8 \mathrm{Kev}\end{array}$ & 8.0 & 0.993 & 6.38 & 14.3 & 10.9 & 6.73 & 3.28 \\
\hline${ }^{86} \mathrm{Y}$ & 4.0 & 0.555 & 4.85 & 26.0 & 9.59 & 4.90 & 2.14 \\
\hline $\begin{array}{c}T_{1 / 2}=0.614 \mathrm{~d} \\
E \gamma=1076.0 \mathrm{keV}\end{array}$ & 8.0 & 0.344 & 1.78 & 5.07 & 4.09 & 2.47 & 1.21 \\
\hline${ }^{85} Y$ & 4.0 & 0.311 & 2.49 & 17.5 & 5.93 & 2.87 & 1.42 \\
\hline $\begin{array}{l}T_{1 / 2}=d \\
E \gamma=k e V\end{array}$ & 8.0 & 0.148 & 0.918 & 3.07 & 2.58 & 1.64 & 0.852 \\
\hline
\end{tabular}

Table 3. Results (isotope production- parameter B) from experiment in march 2011 with deuteron beam $6.0 \mathrm{GeV}$.

Y-88 spatial distribution based on lines 898.042 and $1836.063 \mathrm{keV}$

a)

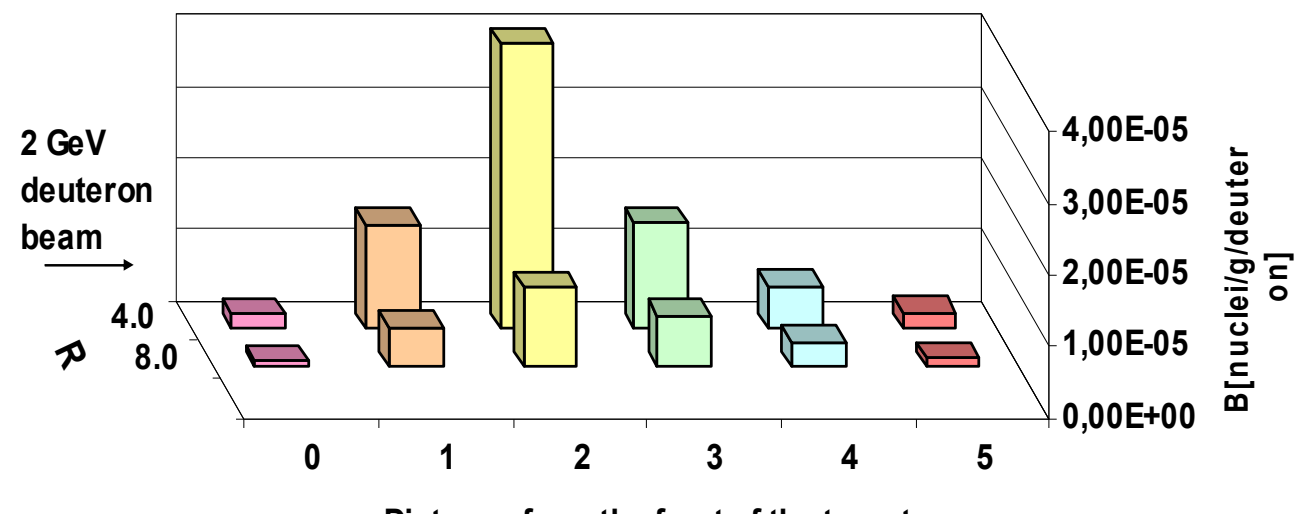

Distance from the front of the target

Fig. 3 Spatial distribution (radial \& axial) of Y-88 production. The deuteron beam $2 \mathrm{GeV}$. 
Y-88 spatial distribution based on lines 898.042 and $1836.063 \mathrm{keV}$

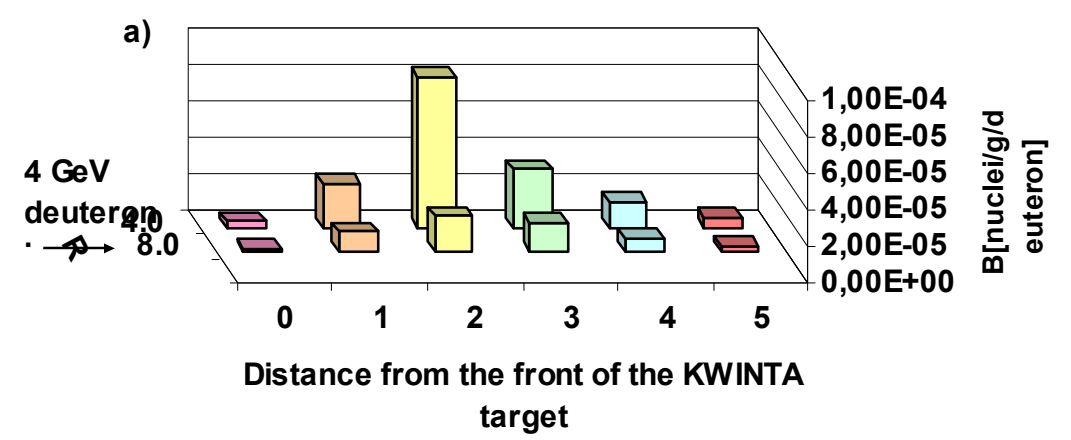

Fig. 4 Spatial distribution (radial \& axial) of Y-88 production. The deuteron beam $4 \mathrm{GeV}$.

Y-88 spatial distribution based on lines 898.042 and $1836.063 \mathrm{keV}$

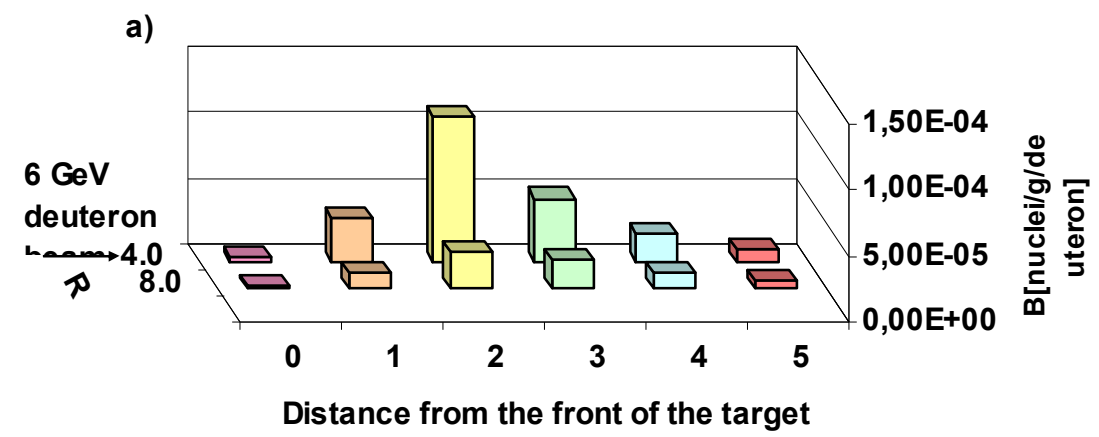

Fig. 5 Spatial distribution (radial \& axial) of Y-88 production. The deuteron beam $6 \mathrm{GeV}$

\section{Average high energy neutron flux inside the Quinta $U / U$ assembly.}

To evaluate the high energy neutron field inside the Quinta assembly we need the microscope cross section for the $(\mathrm{n}, \mathrm{xn}){ }^{89} \mathrm{Y}$ reaction. The experimental data for those reaction reactions are available only for ${ }^{89} Y(n, 2 n){ }^{88} Y$ and ${ }^{89} Y(n, 3 n){ }^{87} Y$ reaction (EXFOR data base [4]). That is why we used TALYS code [5], [6] for calculation all $(\mathrm{n}, \mathrm{xn})$ reactions cross sections (Fig. 7). It has been compared with experimental data with good results. 


\section{Y-85 spatial distribution based on gamma line $\mathrm{keV}$}

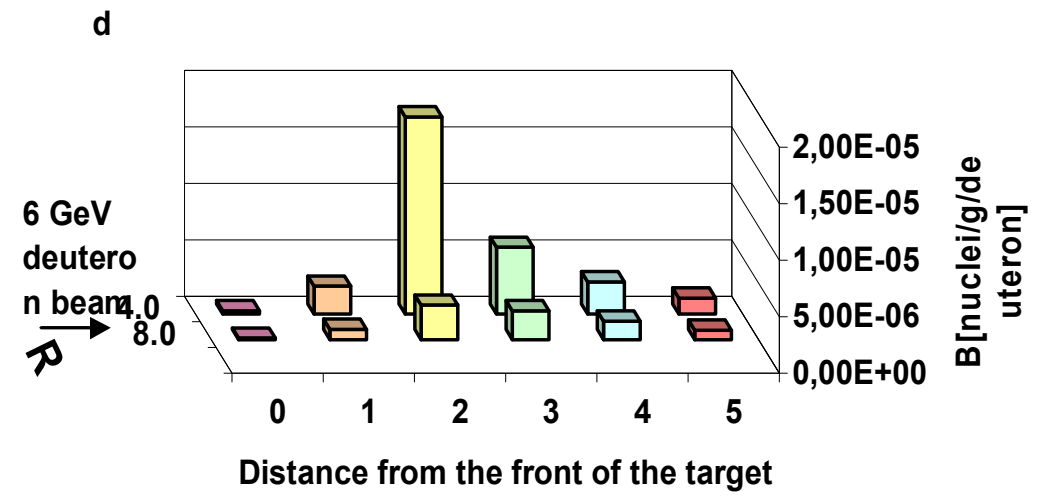

Fig. 6 Spatial distribution (radial \& axial) of Y-85 production. The deuteron beam $6 \mathrm{GeV}$.

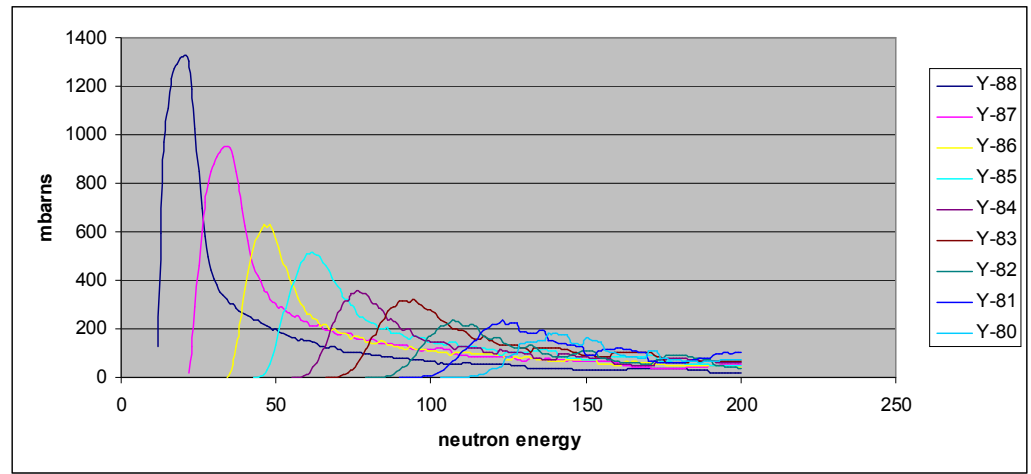

Fig. 7. TALYS microscopic cross sections for all ${ }^{89} Y(n, x n)$ reactions. [7]

As a next step, we take experimental data of Y-88, Y-87 and Y-86 isotopes produced. In the earlier experiments we can to have good detection only for three isotopes Y-88, Y-87 and Y-86 so we have limited our analysis to the same three isotopes in order to make easier comparison between them. We have determined isotope production per one gram of sample and per one beam deuteron at specified positions of the $\mathrm{U} / \mathrm{U}$ assembly and we can evaluate three average high energy neutron fluxes in each Yttrium -89 detectors location for certain energy ranges. The following three threshold energy $11.5,20.8$ and $32.7 \mathrm{MeV}$ for the reactions ${ }^{89} \mathrm{Y}(\mathrm{n}, 2 \mathrm{n}),{ }^{89} \mathrm{Y}(\mathrm{n}, 3 \mathrm{n})$ and ${ }^{89} \mathrm{Y}(\mathrm{n}, 4 \mathrm{n})$ give us the first two energy ranges $(11.5-20.8 \mathrm{MeV})$ and $(20.8-32.7 \mathrm{MeV})$ of the neutron fluxes $\overline{\phi_{1}}$ and $\overline{\phi_{2}}$. The third range begins at the energy $32.7 \mathrm{MeV}$ and ends at the energy $100 \mathrm{MeV}$, when the microscopic cross section is comparatively low with the maximum 
cross section of ${ }^{89} \mathrm{Y}(\mathrm{n}, 4 \mathrm{n}){ }^{86} \mathrm{Y}$ reaction where is evaluated the neutron flux $\overline{\phi_{3}}$. Combining the linear equations [8], [9] we finally have three equations (1), (2), (3) for unknown neutron fluxes. As we see, beside the experimental data (parameter B) we need only microscopic cross section and some physical constants.

$$
\begin{aligned}
& \overline{\phi_{1}}=\frac{C}{\overline{\sigma_{11}}}\left[B^{88}-B^{87} \frac{\overline{\sigma_{12}}}{\overline{\sigma_{22}}}+B^{86}\left(\frac{\overline{\sigma_{23}} \overline{\sigma_{12}}}{\overline{\sigma_{33}} \overline{\sigma_{22}}}-\frac{\overline{\sigma_{13}}}{\overline{\sigma_{33}}}\right)\right] \\
& \overline{\phi_{2}}=\frac{C}{\overline{\sigma_{22}}}\left[B^{87}-B^{86} \frac{\overline{\sigma_{23}}}{\overline{\sigma_{33}}}\right] \\
& \overline{\phi_{3}}=\frac{C}{\overline{\sigma_{33}}} B^{86} \quad ; \quad\left(C=\frac{S G^{89}}{A t}\right)
\end{aligned}
$$

where $B^{88}, B^{87}, B^{86}$ - measured isotopes of ${ }^{88} \mathrm{Y},{ }^{87} \mathrm{Y}$ and ${ }^{86} \mathrm{Y}$ respectively per one gram of detector and per one beam deuteron

$\overline{\sigma_{11}} \cdot-\overline{\sigma_{33}}-$ microscopic cross section of the measured isotopes for the reaction (n, xn) in the three chosen energy ranges,

$\overline{\phi_{1}}, \overline{\phi_{i}} \cdot \overline{\phi_{3}}$ - unknown average neutron fluxes in the three chosen energy ranges.

$\mathrm{C}$ - physical constants

The following average microscopic cross sections for the reactions ${ }^{89} Y(n, 2 n){ }^{88} Y,{ }^{89} Y(n, 3 n){ }^{87} Y$ and ${ }^{89} \mathrm{Y}(\mathrm{n}, 4 \mathrm{n}){ }^{86} \mathrm{Y}$ in the three chosen energy ranges are used to make calculations using the formulas (1), (2) and (3). We calculated it as algebraic average cross section in each energy rate respectively - data from TALYS calculations Fig. 7. Example of calculation results we can see in the Table 4, and example of graphs we can see in Figs 8 and 9.

$\overline{\sigma_{11}}=1.030$ barn for ${ }^{89} \mathbf{Y}(\mathbf{n}, 2 \mathrm{n}){ }^{88} \mathrm{Y}$ reaction

$\overline{\sigma_{12}}=\mathbf{0 . 7 3 3}$ barn for ${ }^{89} \mathrm{Y}(\mathrm{n}, \mathbf{2 n})^{88} \mathrm{Y}$ reaction

$\overline{\sigma_{13}}=\mathbf{0 . 1 5 0}$ barn for ${ }^{89} \mathrm{Y}(\mathrm{n}, \mathbf{2 n})^{88} \mathrm{Y}$ reaction

$\overline{\sigma_{22}}=0.569$ barn for ${ }^{89} Y(n, 3 n){ }^{87} Y$ reaction

$\overline{\sigma_{23}}=0.288$ barn for ${ }^{89} Y(n, 3 n){ }^{87} Y$ reaction

$\overline{\sigma_{33}}=0.252$ barn for ${ }^{89} \mathrm{Y}(\mathrm{n}, 4 \mathrm{n}){ }^{86} \mathrm{Y}$ reaction in the energy range 11.5-20.8 $\mathrm{MeV}$

in the energy range 20.8-32.7 MeV

in the energy range 32.7-100 $\mathrm{MeV}$

in the energy range $20.8-32.7 \mathrm{MeV}$

in the energy range 32.7-100 $\mathrm{MeV}$

in the energy range 32.7-100 $\mathrm{MeV}$ 
Those results are quite difficult to compare. That is why we prepared special comparison with help us to test our results. Comparison of average neutron flux density per deuteron and per unit energy of deuteron, is performed for the three deuteron beams of energies equal to 2, 4 and $6 \mathrm{GeV}$. In fact it is expected that the curves of the average neutron flux density per deuteron and per unit energy of deuteron beam $(1 \mathrm{GeV})$ should overlap each other what is shown on the example figure Fig.10. In Fig. 10 the overlapping of the courves is excellent, in the other figures is little worse sometimes.

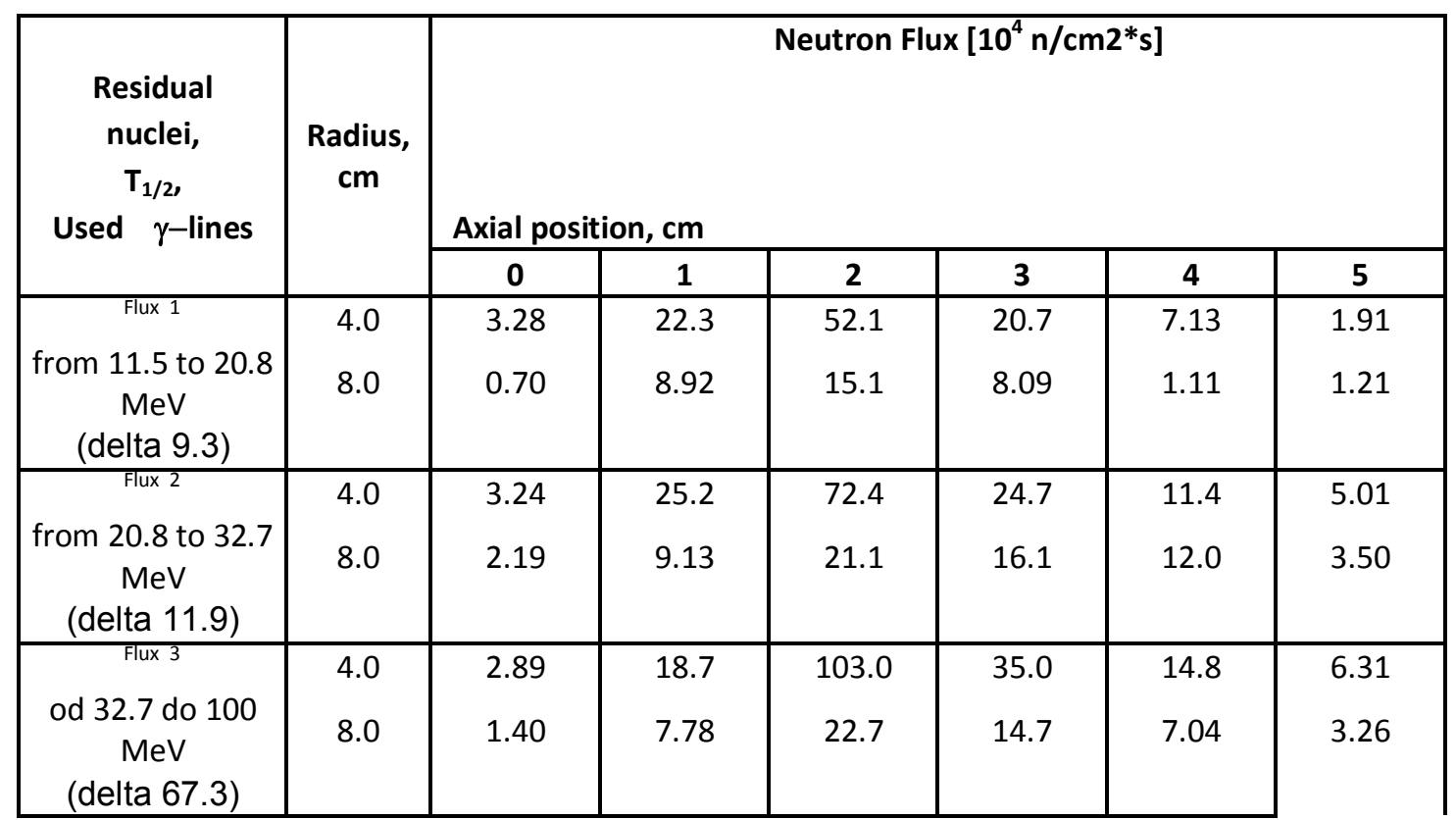

Table 4 Evaluated neutron flux distribution in the Quinta assembly for three energy ranges for the deuteron beam of $2.0 \mathrm{GeV}$

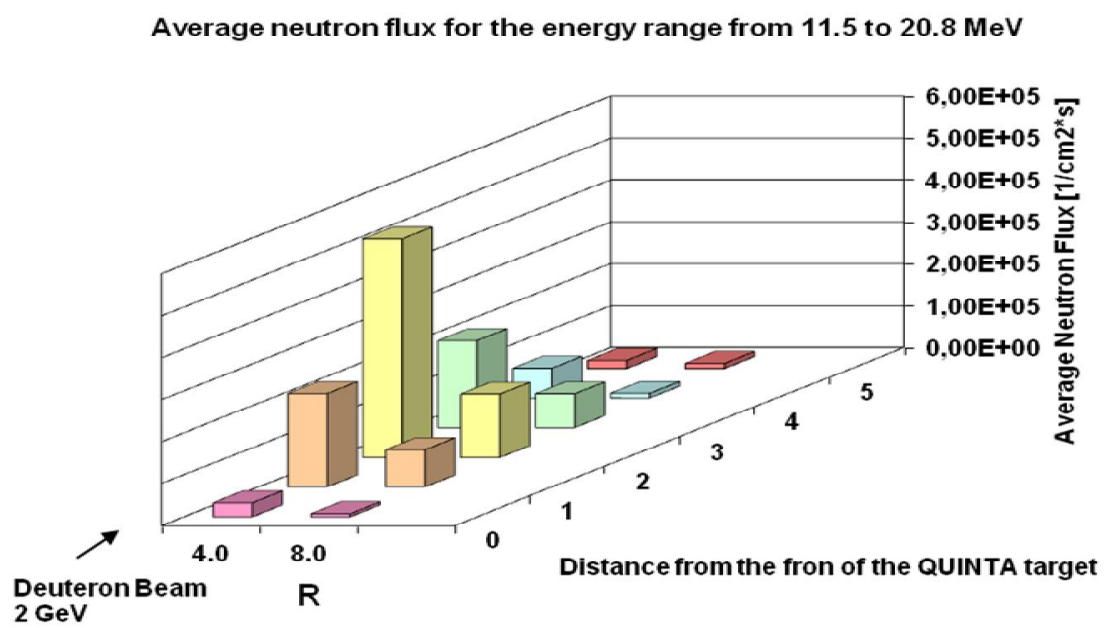

Fig. 8. Spatial average neutron flux distribution in the Quinta assembly for the neutron energy range $(11.5-20.8) \mathrm{MeV}$ for the deuteron beam of $2.0 \mathrm{GeV}$. 


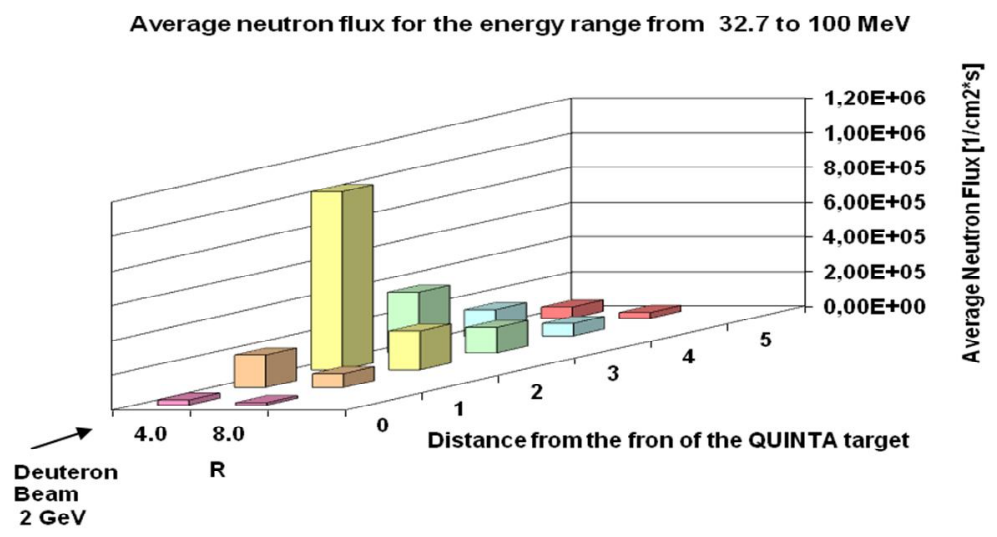

Fig. 9. Spatial average neutron flux distribution in the Quinta assembly for the neutron energy range (32.7 - 100) $\mathrm{MeV}$ for the deuteron beam of $2.0 \mathrm{GeV}$.

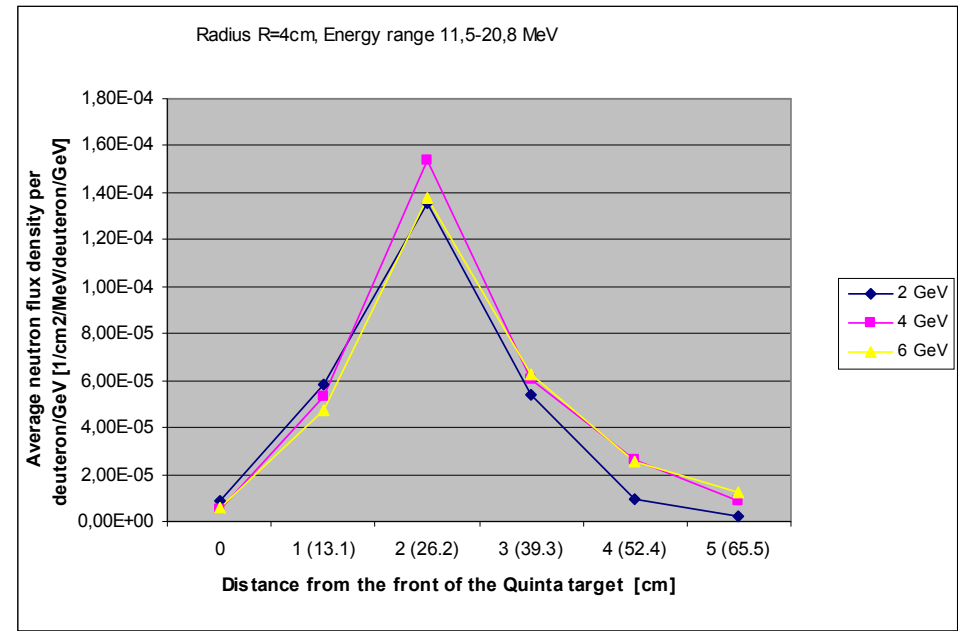

Fig. 10. Average neutron flux density per deuteron and its energy in function of length for $\mathrm{R}=4 \mathrm{~cm}$ for three beam energies $(2,4,6 \mathrm{GeV})$ in the neutron energy range $11.5-20.8 \mathrm{MeV}$

\section{Monte Carlo (MCNPX) Calculations for the Quinta U/U assembly [10].}

Using the MCNPX 2.6 code, the geometry of the Quinta U/U assembly and the applied materials was simulated. Calculations of isotope production in each Yttrium-89 detectors during 2.0 GeV deuteron irradiation were prepared (see Figs 11 and 12). EXFOR data base were used in order to apply the microscopic cross sections for $(n, 2 n)$ and $(n, 3 n)$ reactions of yttrium in the code. The calculations do not take into account such reactions as $(\gamma, n),(p, d),(p, p n),(d, t),(d, p 2 n)$ because of microscopic cross sections lack for the reactions. Number of simulations was equal $10^{6}$. The data are normalized to one source deuteron. We can see that comparisons are quite good (Figs 11 and 12). 


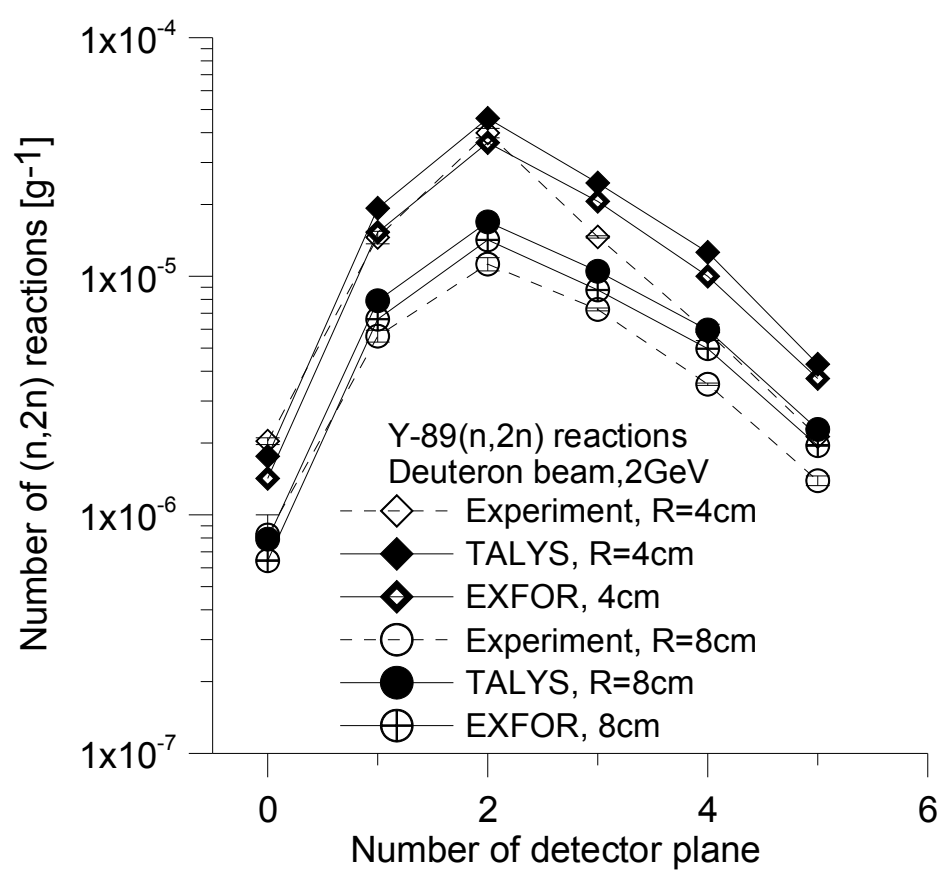

Fig. 11. Comparison of experimental and computational axial distribution of isotope Y-88 production at radial distance equal to $4 \mathrm{~cm}$ and $8 \mathrm{~cm}$ for the deuteron beam energy of $2 \mathrm{GeV}$.

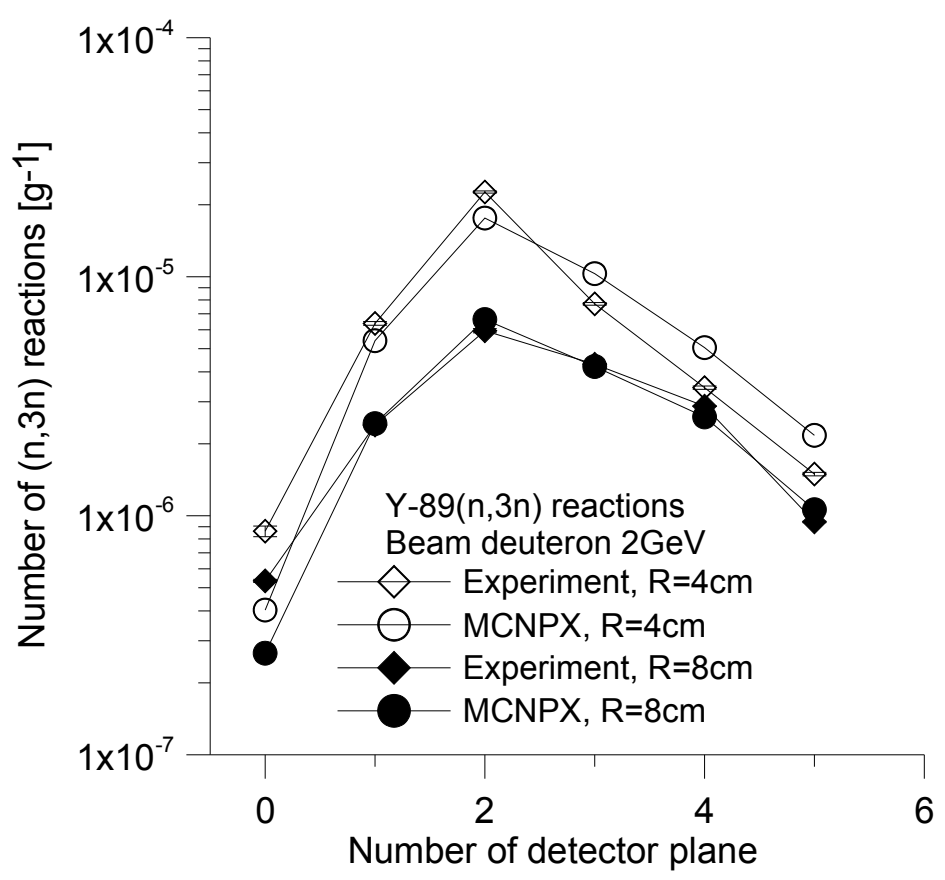

Fig. 12. Comparison of experimental and computational axial distribution of isotope Y-87 production at radial distance equal to $4 \mathrm{~cm}$ and $8 \mathrm{~cm}$ for the deuteron beam energy of $2 \mathrm{GeV}$. 


\section{Conclusion}

Y-89 is a very good threshold detector for high energy neutron energy spectrum measurement and easy for analyses. Shape of spatial distribution of Y-88, Y-87 Y-86 and Y-85 isotopes of the Yttrium-89 detectors in the U/U-QUINTA assembly produced by the neutrons generated in the assembly irradiated by the relativistic deuteron beam of $2 \mathrm{GeV}, 4 \mathrm{GeV}$ and 6 $\mathrm{GeV}$ energies in general reflects the shape of the evaluated average high energy neutron fluxes in the Yttrium-89 detectors. We will compare this result with results coming from other experiments.

\section{6. $\quad$ References}

[1] Программа подготовки и проведения комплекса экспериментов на установке «Квинта» в декабре 2010 г. - Dubna Russia 2010

[2] J. Frana - Program DEIMOS32 for Gamma Ray Spectra Evaluation. Radioanal. and Nucl. Chem., V. 257, p.583, 2003.

[3] Ondřej Svoboda - Experimental Study of Neutron Production and Transport for ADTT Dissertation Thesis - Czech Technical University in Prague, 2010

[4] Experimental Nuclear Reaction Data; EXFOR/CSISRS

[5] Koning A. J., Hilaire S., Duijvestijn M. C. TALYS: Comprehensive Nuclear Reaction Modeling, International Conference on Nuclear Data for Science and Technology 2004, Santa Fe, New Mexico, 26th September-1st October 2004. AIP Conference Proceedings, Volume 769 (2005)1154-9,

[6] TALYS-1.0 : A Nuclear reaction code. A.J. Koning, S.Hilaire, M.Duijvestijn. www.talys.eu

[7] M. Majerle TALYS Calculation Nuclear Physics Institute of ASCR, Czech Republic

[8] M. Bielewicz, S. Kilim, E. Strugalska-Gola, M. Szuta, A. Wojciechowski, M.I. Krivopustov, A.V. Pavliouk, I. Adam, A. Krasa, A. Kugler, M. Majerle,V. Wagner; On results of Y-89 irradiation with deuteron beam on U/Pb-assembly "Energy plus Transmutation" using Nuclotron (JINR, Dubna); Proceedings of the XVIII Inter. Baldin Seminar on High Energy Physics Problems, Dubna, Russia, Vol.I, p.205-213, E1-2-2008, 2008.

[9] M.Bielewicz, S. Kilim, E. Strugalska-Gola, M. Szuta, A. Wojciechowski; Yttrium as a New Threshold Detector for Fast Neutron Energy Spectrum (>10 MeV) Measurement, J. Korean Phys. Soc. Vol.59 No 2 p.2014, 2011

[10] Judith F. Briesmeister, MCNP - A General Monte Carlo N-Particle Transport Code, La-12625M Version 4b, Manual, March 1997.

[11] V. Wagner, O. Svoboda, M. Suchopár; The intensity of the deuteron beams on Kvinta and Gamma-3 targets (experiment March 2011) 